\title{
Monitoring and Mapping Vineyard Water Status Using Non-Invasive Technologies by a Ground Robot
}

\author{
Juan Fernández-Novales ${ }^{1,2}$, Verónica Saiz-Rubio ${ }^{3}{ }^{\mathbb{D}}$, Ignacio Barrio ${ }^{1,2}$, Francisco Rovira-Más ${ }^{3}$, \\ Andrés Cuenca-Cuenca ${ }^{3}$, Fernando Santos Alves ${ }^{4}$, Joana Valente ${ }^{4}$, Javier Tardaguila ${ }^{1,2}$ (i) and \\ María Paz Diago ${ }^{1,2, *}$
}

1 Televitis Research Group, University of La Rioja, 26006 Logroño, Spain; juan.fernandezn@unirioja.es (J.F.-N.); ignacio.barrio@unirioja.es (I.B.); javier.tardaguila@unirioja.es (J.T.)

2 Institute of Grapevine and Wine Sciences (University of La Rioja, Consejo Superior de Investigaciones Científicas, Gobierno de La Rioja), 26007 Logroño, Spain

3 Agricultural Robotics Laboratory (ARL), Universitat Politècnica de València, Camino de Vera, s/n., 46022 Valencia, Spain; vesairu@upv.es (V.S.-R.); frovira@dmta.upv.es (F.R.-M.); ancuecu1@upv.es (A.C.-C.)

4 Symington Family Estates, Vinhos SA, Travessa Barão de Forrester 86, 4431-901 Vila Nova de Gaia, Portugal; fernando.alves@symington.com (F.S.A.); Joana.Valente@symington.com (J.V.)

* Correspondence: maria-paz.diago@unirioja.es; Tel.: +34-94-129-9731

\section{check for}

updates

Citation: Fernández-Novales, J.; Saiz-Rubio, V.; Barrio, I.; Rovira-Más,

F.; Cuenca-Cuenca, A.; Santos Alves, F.; Valente, J.; Tardaguila, J.; Diago, M.P. Monitoring and Mapping Vineyard Water Status Using Non-Invasive Technologies by a Ground Robot. Remote Sens. 2021, 13, 2830. https://doi.org/10.3390/ rs13142830

Academic Editor: Javier J. Cancela

Received: 26 May 2021

Accepted: 15 July 2021

Published: 19 July 2021

Publisher's Note: MDPI stays neutral with regard to jurisdictional claims in published maps and institutional affiliations.

Copyright: (c) 2021 by the authors. Licensee MDPI, Basel, Switzerland. This article is an open access article distributed under the terms and conditions of the Creative Commons Attribution (CC BY) license (https:/ / creativecommons.org/licenses/by/ $4.0 /)$.
Abstract: There is a growing need to provide support and applicable tools to farmers and the agroindustry in order to move from their traditional water status monitoring and high-water-demand cropping and irrigation practices to modern, more precise, reduced-demand systems and technologies. In precision viticulture, very few approaches with ground robots have served as moving platforms for carrying non-invasive sensors to deliver field maps that help growers in decision making. The goal of this work is to demonstrate the capability of the VineScout (developed in the context of a H2020 EU project), a ground robot designed to assess and map vineyard water status using thermal infrared radiometry in commercial vineyards. The trials were carried out in Douro Superior (Portugal) under different irrigation treatments during seasons 2019 and 2020. Grapevines of Vitis vinifera L. Touriga Nacional were monitored at different timings of the day using leaf water potential $\left(\mathbf{\Psi}_{1}\right)$ as reference indicators of plant water status. Grapevines' canopy temperature $\left(T_{c}\right)$ values, recorded with an infrared radiometer, as well as data acquired with an environmental sensor $\left(\mathrm{T}_{\mathrm{air}}, \mathrm{RH}\right.$, and AP) and NDVI measurements collected with a multispectral sensor were automatically saved in the computer of the autonomous robot to assess and map the spatial variability of a commercial vineyard water status. Calibration and prediction models were performed using Partial Least Squares (PLS) regression. The best prediction models for grapevine water status yielded a determination coefficient of cross-validation $\left(\mathrm{r}^{2}{ }_{\mathrm{cv}}\right)$ of 0.57 in the morning time and a $\mathrm{r}_{\mathrm{cv}}{ }_{\mathrm{cv}}$ of 0.42 in the midday. The root mean square error of cross-validation (RMSE $\mathrm{Cv}_{\mathrm{cv}}$ ) was $0.191 \mathrm{MPa}$ and $0.139 \mathrm{MPa}$ at morning and midday, respectively. Spatial-temporal variation maps were developed at two different times of the day to illustrate the capability to monitor the grapevine water status in order to reduce the consumption of water, implementing appropriate irrigation strategies and increase the efficiency in the real time vineyard management. The promising outcomes gathered with the VineScout using different sensors based on thermography, multispectral imaging and environmental data disclose the need for further studies considering new variables related with the plant water status, and more grapevine cultivars, seasons and locations to improve the accuracy, robustness and reliability of the predictive models, in the context of precision and sustainable viticulture.

Keywords: agricultural robotics; non-invasive proximal sensing; water stress; chemometrics; precision viticulture 


\section{Introduction}

Agricultural robots are mobile robotic machines that assist or carry out agricultural practices in the field, in the context of precision farming operations, or to substitute humans in certain heavy, tedious tasks or difficult environments [1]. In the framework of robotic scouting, automated sensing of biophysical or biochemical features of the crop, resulting from its interaction with biotic or abiotic factors of its surrounding environment is usually conducted through proximal remote sensing, with non-invasive sensors operating contactless [2]. A big challenge of this robotic-based monitoring is to reach levels of accuracy and precision that are appropriate for reliable decision making about crop management, especially considering that variations in the environmental conditions, and the variability of plant responses to the environment may affect the quality of the measurements [1]. Agricultural ground robots enable the automated collection of large amounts of data, with a suite of different and complementary sensors, under widely varying environmental conditions, that may be used to build regression models or classification algorithms to yield robust estimations of the agronomical parameters of interest. Likewise, in the field of viticulture, several scouting ground robots have been developed in the last decade, mostly as research prototypes. Examples include Vinerobot [3], for the assessment of canopy nitrogen status and berry anthocyanins, Vinbot [4] for yield estimation, Phenobot [5] for canopy assessment, GRAPE [6] for canopy density appraisal and pheromone distribution, and BACCHUS, for fruit health and yield estimation (https:/ / bacchus-project.eu/overview/summary/, accessed on 18 November 2020), among others. While all these grapevine canopy and berry features are of great importance, the assessment of the vine water status using autonomous ground robots is also very relevant, as the effective implementation of sustainable water management and irrigation in viticulture calls for objective and representative monitoring of the vineyard water status and its variability.

Land and soil are variable, which contributes to, and mainly cause a phenomenon called spatial variability. This involves water and nutrient inter and intra-plot availability potentially changing, which has a strong influence on both plant development and physiology, as well as on crop production and composition $[7,8]$. In this context, the usefulness of high-spatial-resolution information regarding plant water status zones within plots has been noted by several authors $[9,10]$ in order to provide plants with different water requirements with different irrigation doses.

Irrigation scheduling is currently defined using different approaches, from soil water measurements or balance estimates to environmental modeling and plant stress indicators [11]. However, many of these methods monitor only a small, limited number of plants; therefore, they are unsuited to detecting spatial variation in water status within a vineyard [12].

One of the technologies suitable to be incorporated in agricultural robots is thermography. It can be applied for monitoring canopy temperature, since during leaf transpiration, water is lost through stomata and leaf temperature decreases, making it an indicator of plant water status. However, if the transpiration process stops, because heat dissipation in the leaf no longer takes place, leaf temperature increases [13]. Thermal cameras of different resolution and prices [14], even smartphone-based [15], can be used as portable devices for the estimation of plant water status and to assist in the setup of irrigation schedules, but time and labor demand, together with the limited number of manual measurements are pitfalls that still remain. While the latter has been partially solved by aerial thermography, covering large field extensions [16], in some crops, such as grapevines, aerial observation provides thermal imagery in which pixels often mix canopy and soil information, which complicates further analyses as they need to be effectively separated. This presents a unique opportunity to develop thermal systems for grapevine water status estimation using ground robots. These would be capable of automated gathering of canopy information from a close lateral point of view [17] and of covering large areas, assessing vineyard water status variability [18]. Lateral thermography of grapevines from conventional manned ground vehicles has been successfully tested using thermal cameras [18], and good relation- 
ships were obtained between the predicted and observed stem water potential $\left(\Psi_{\mathrm{s}}\right)$, which was used as plant water status indicator. While this was a big step forward towards on-thego thermography, the processing of the acquired thermal images after monitoring, to retain only the canopy information is not a straightforward process [19], which requires time and expertise. In an extensive review of the use of ground-based thermography to assess plant water status in agriculture, the advantages of infrared radiometers vs. thermal cameras were postulated [20]. Infrared radiometers are sensors that measure infrared radiation (in the range between 8 to $14 \mu \mathrm{m}$ ) and can be considered as a simplified version of thermal cameras. While thermography provides measurements of the temperature of the grapevine canopy, a radiometer provides an averaged value of the target's surface temperature of the measuring spot. The interpretation of a thermal image is not simple, as leaves in the measuring spot of the targeted canopy may undergo different environmental conditions and leaf orientations, both factors potentially affecting the thermal measurement [21]. Given this, the use of ancillary information, both environmental (e.g., air temperature, relative humidity) and/or retrieved from other non-invasive sensors also measuring the canopy from a moving vehicle may help to complement and improve the assessment of the plant water status.

The VineScout ground robot is a prototype developed in the EU H2020 VineScout project (http:/ / vinescout.eu/web/, accessed on 5 December 2020), autonomously driven with the assistance of local perception sensors (stereo camera, LiDAR and ultrasound sensors) for navigation and safeguarding, aimed at monitoring and mapping plant water status in commercial vineyards to assist grapegrowers in decision making about irrigation scheduling. This work presents the sensing system embedded in the VineScout robot, based on thermal infrared radiometry, and the developed models for the automated assessment and mapping of vineyard water status. The goal of this study was to evaluate and map the vineyard water status using several non-destructive technologies, such as thermography, multispectral imaging and a suite of environmental sensors embedded in an autonomous ground robot.

\section{Materials and Methods}

\subsection{Vineyard Site and Experimental Layout}

This research study was conducted in a commercial vineyard located in Douro Superior (Portugal), during seasons 2019 and 2020. The field was a 2.2 ha vineyard located in Junqueira (Portugal) (Lat. 41 $14^{\prime} 39.27^{\prime \prime}$, Long. $7^{\circ} 6^{\prime} 55.10^{\prime \prime}, 151 \mathrm{~m}$ asl). Grapevines of Touriga Nacional (Vitis vinifera L.) were planted in 2014, following an east-west orientation, with spacing of $2.10 \mathrm{~m}$ between rows and $1 \mathrm{~m}$ between vines, on a vertical shoot position (VSP) trellis with a unilateral cordon Royat. To induce a wide variability of grapevine water status, different water regimes were applied to several rows of the studied vineyard (Figure 1). The irrigation scheduling and the irrigation amounts were managed according to leaf water potential $\left(\Psi_{1}\right)$ measurements carried out regularly by the winery. In 2019 , three different water regimes were established in six rows with two replicates for each water regime. The three irrigation treatments applied corresponded to $15 \%, 30 \%$ and $60 \%$ of crop reference $\mathrm{ET}_{\mathrm{C}}$ (Figure 1a). In 2020, only the $15 \%$ and $60 \% \mathrm{ET}_{\mathrm{c}}$ treatments were maintained (Figure $1 b$ ), and these are detailed in Table 1 . The daily reference evapotranspiration was computed with the Penman-Monteith equation [22] according to the Food and Agriculture Organization (FAO), and using the meteorological data provided by the local weather station sited in the vineyard. Each row included 21 blocks of five vines each. Of these, in each row only five blocks were measured in 2019 (Figure 1a), and six blocks in season 2020 (Figure 1b). For each block, five consecutive plants were monitored and considered as the "measuring unit". 

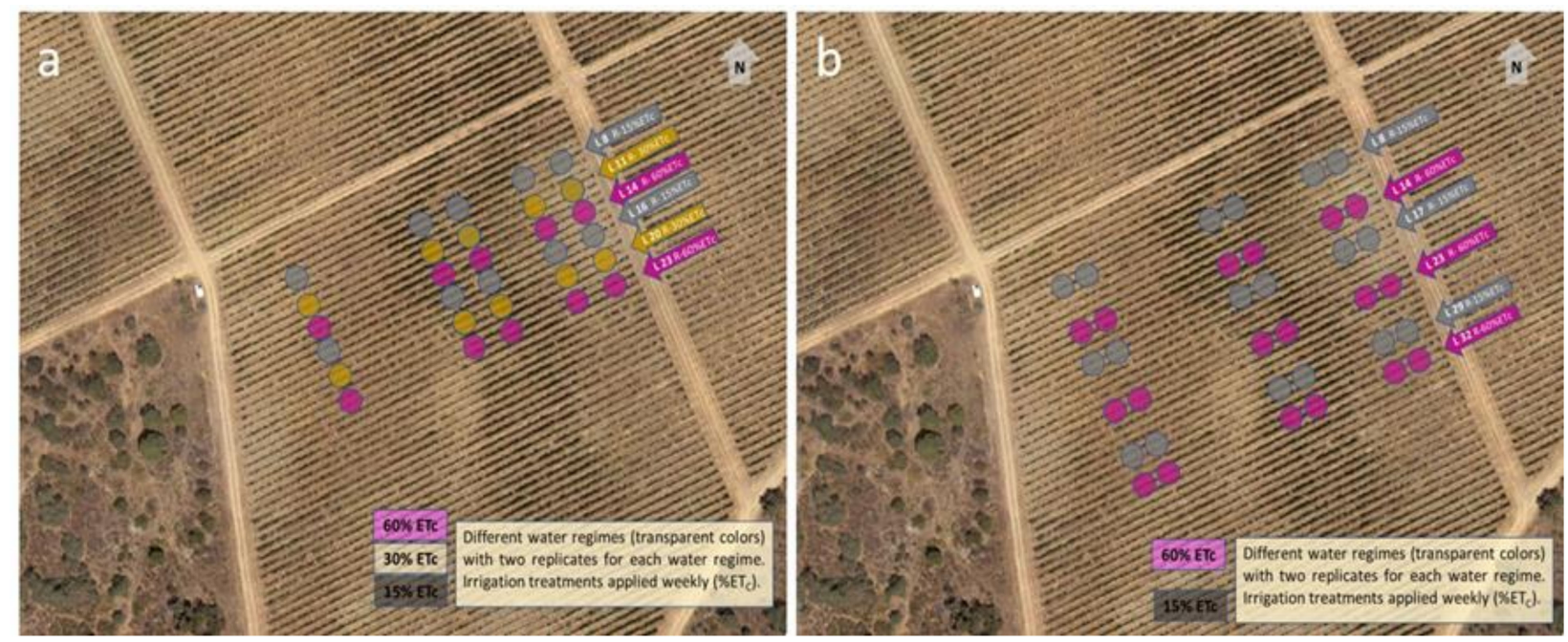

Figure 1. Irrigation treatments applied and reference blocks for seasons 2019 (a) and 2020 (b).

Table 1. Irrigation rates (expressed as \% of $\mathrm{ET}_{\mathrm{c}}$ ) applied to reference rows in the monitored vineyard in seasons 2019 and 2020 (Aug: August; Sept: September).

\begin{tabular}{|c|c|c|c|c|c|}
\hline $\begin{array}{l}\text { Irrigation } \\
\text { Regime }\end{array}$ & $\begin{array}{c}{ }^{1} \mathrm{ET}_{0}(\mathrm{~mm}) \\
\text { Aug }\end{array}$ & $\begin{array}{c}{ }^{1} \mathrm{ET}_{0}(\mathrm{~mm}) \\
\text { Sept }\end{array}$ & ${ }^{2} \mathrm{Kc}$ & $\begin{array}{c}\text { Rate Aug } \\
\text { (1/ha Week) }\end{array}$ & $\begin{array}{c}\text { Rate Sept } \\
\text { (1/ha Week) }\end{array}$ \\
\hline \multicolumn{6}{|c|}{ Season 2019} \\
\hline $15 \%$ & 166 & 131 & 0.7 & 44,000 & 36,000 \\
\hline $30 \%$ & 166 & 131 & 0.7 & 86,000 & 72,000 \\
\hline $60 \%$ & 166 & 131 & 0.7 & 176,000 & 136,000 \\
\hline \multicolumn{6}{|c|}{ Season 2020} \\
\hline $15 \%$ & 177 & 125 & 0.7 & 48,000 & 32,000 \\
\hline $60 \%$ & 177 & 125 & 0.7 & 184,000 & 131,000 \\
\hline
\end{tabular}

${ }^{1} \mathrm{ET}_{0}$ : reference evapotranspiration. ${ }^{2} \mathrm{Kc}$ : crop coefficient.

\subsection{Autonomous Ground Robot}

An autonomous ground vehicle developed in the frame of the H2020 EU project Vinescout (http: / / vinescout.eu/web /, accessed on 5 December 2020) was used in the trials to record massive field data. The external dimensions of the VineScout robot are $1 \mathrm{~m}$ wide, $1.2 \mathrm{~m}$ long, and $1.2 \mathrm{~m}$ tall (with the GPS antenna folded) (Figure 2a). The robot was powered by a stack of three electric Lithium-ion batteries supplying 24 VDC and $195 \mathrm{Ah}$. The navigation system was based on local perception [23] and combined a 3D stereo/TOF (O3M150, ifm electronic $\mathrm{GmbH}$, Essen, Germany), a non-rotational LiDAR rangefinder (Multi-Ray LED Scanner OMD8000-R2100-R2-2V1, Pepperl + Fuchs, Mannheim, Germany), and four ultrasonic sensors (UC2000 30GM IUR2 V15, Pepperl + Fuchs, Mannheim, Germany). The central computing unit mounted in the robot was an industrial, fan-less computer that managed the sensors through a data acquisition card (NI USB-6216, National Instruments, Austin, TX, USA). The crop sensors on board the robot faced the right side of the canopy (Figure 2b). 


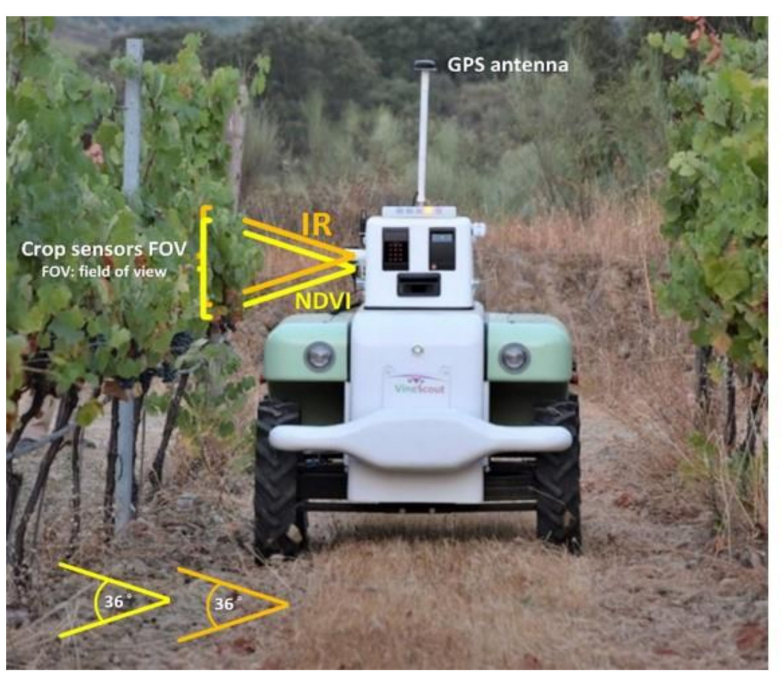

(a)

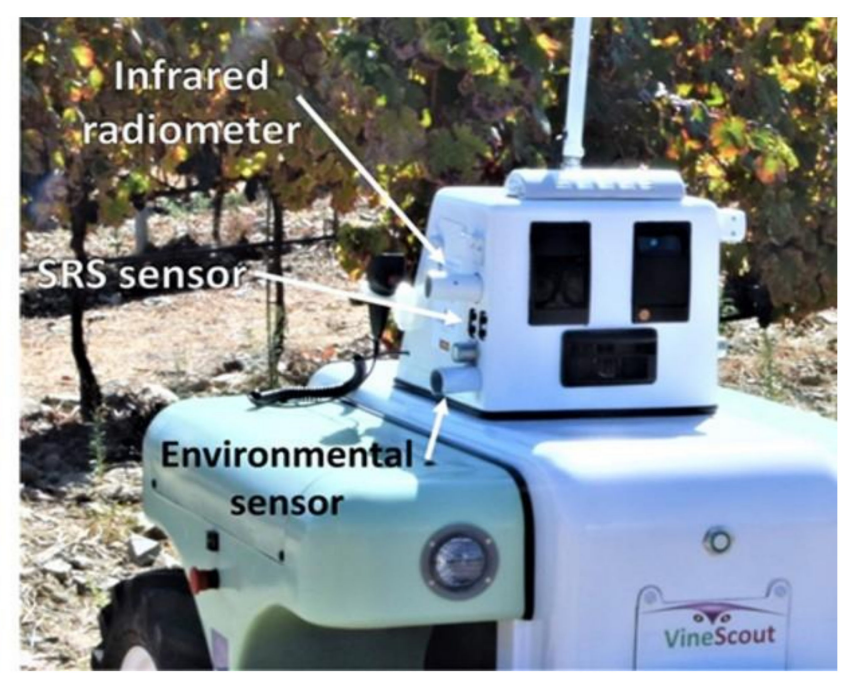

(b)

Figure 2. (a) Vinescout VS-3 autonomous ground vehicle used to monitor grapevine water status during 2020 season. (b) Detail of the crop sensing unit used for on-the-go measurement of water status.

The robot was manually guided with a joystick to the initial position set by the vineyard manager, from where it started taking data to build the water status map. After confirming that the GPS was working correctly, the operator turned on the data recording button of the graphic user interface to start recording all the data, and the autonomous mode to start moving. The robot travelled at a speed of $1.5 \mathrm{~km} / \mathrm{h}$. The crop measuring cycle operated at $1.8 \mathrm{~Hz}$, and it included the measurement of the following three crop sensors: the infrared radiometer, the multispectral NDVI sensor, and the environmental sensor suite.

The robot navigated autonomously (URL: https:/ / doi.org/10.5281/zenodo.4719849, accessed on 26 April 2021), following the centerline between rows. When the robot detected the absence of vegetation to be monitored with the right ultrasonic sensors, crop data was not recorded, for example, in headlands or when canopy gaps existed. When the map was complete, according to the number of rows selected by the operator at initiation, the operators could retrieve the field data with a pen drive through one of the USB ports located in the robot.

\subsection{Sensing Technologies}

On-the-go thermal measurements were carried out using an infrared radiometer mounted in the VineScout prototype to estimate vine water status. The infrared radiometer SI-421 (Apogee instrument Inc., Logan, Utah, USA) was used to measure the surface canopy temperature (Figure 3). The IR radiometer was setup to sample at $1.8 \mathrm{~Hz}$ data acquisition rate, and its field of view (FOV) was $36^{\circ}$ (Figure 2a), which results in a circular FOV of approximately $0.3 \mathrm{~m}$ diameter according to the distance from the sensor to the vegetation, as illustrated in Figure 3. This low-cost sensor operates in the waveband range of 8-14 $\mu \mathrm{m}$ with a calibration uncertainty and measurement repeatability of $\pm 2{ }^{\circ} \mathrm{C}$ and less than $0.05^{\circ} \mathrm{C}$, respectively. Specific tests (see in Supplementary Material, Figure S1) to calibrate the infrared radiometer against a thermal camera (ThermaCAM Flir P640, $640 \times 480$ pixels, Flir Systems, Wilsonville, Oregon, USA) were previously conducted and statistical metrics of this calibration can be found in Tables S1 and S2 of the Supplementary Material. 

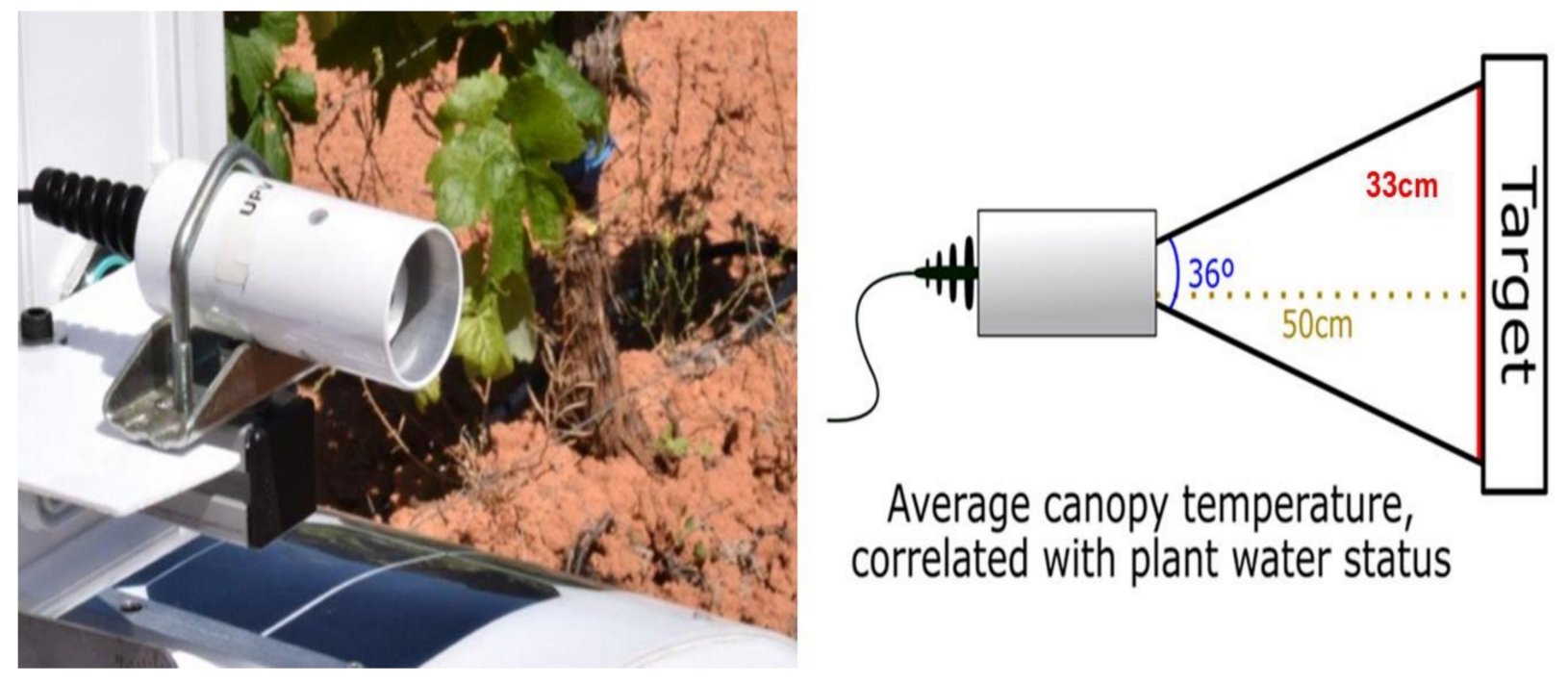

Figure 3. Infrared radiometer SI-421 and scheme showing the distance to the canopy (target), angle and window of measurement.

To have a better description of the environment surrounding each grapevine, an ambient sensor T7311-2 (COMET SYSTEM, s.r.o., Rožnov pod Radhoštěm, Czech Republic) for measuring air temperature, relative humidity and atmospheric pressure in real time was also installed in the robot (Figure $2 b$ ). The accuracy and resolution of the different environmental parameters were: for the temperature sensor $\pm 0.4{ }^{\circ} \mathrm{C}$ and $0.1{ }^{\circ} \mathrm{C}$, for the humidity sensor $\pm 2.5 \% \mathrm{RH}$ from 5 to $95 \%$ at $23^{\circ} \mathrm{C}$ and $0.1 \% \mathrm{RH}$, and for the atmospheric pressure $\pm 1.3 \mathrm{hPa}$ at $23{ }^{\circ} \mathrm{C}$ from 800 to $1100 \mathrm{hPa}$ and $0.1 \mathrm{hPa}$, respectively. The response time of these environmental sensors was fixed to $3.6 \mathrm{~Hz}$. These three variables were measured simultaneously to the canopy temperature with the infrared radiometer.

Multispectral information of the grapevine canopy was also acquired on-the-go simultaneously to thermal measurements. The inclusion of vegetative spectral information as a surrogate of vegetative growth [24] and canopy health status, both factors being determinant of grapevine water use [25], may complement the thermal information gathered by the infrared radiometer. To that end, in season 2019 the $\mathrm{OCI}^{\mathrm{TM}}-\mathrm{M}$ Multispectral Camera (BaySpec Inc., San Jose, CA, USA) was used, while in 2020, a simpler spectral reflectance sensor (SRS) measuring NDVI was employed. The multispectral camera used in 2019 measures at eight spectral bands $(470 \mathrm{~nm}, 560 \mathrm{~nm}, 670 \mathrm{~nm}, 720 \mathrm{~nm}, 780 \mathrm{~nm}, 840 \mathrm{~nm}, 900 \mathrm{~nm}$ and $970 \mathrm{~nm}$ ) covering from visible (VIS) to short-wave near infrared (SW-NIR) region. The camera features high data transfer rates (up to $120 \mathrm{fps}$ ) and represents the eight bands in every image. From the acquired multispectral images, the Normalized Difference Vegetation Index (NDVI) [26] and the Green Normalized Difference Vegetation Index (GNDVI) were computed. Additionally, two spectral bands related with the Chlorophyll (Band $560 \mathrm{~nm}$ ) and water stress (Band $840 \mathrm{~nm}$ ) $[27,28]$ were also tracked. The NDVI is one of the most commonly used vegetation spectral indices. It is a ratio between the near infrared (NIR) and red channels and relates to the plant vigor, vegetative growth and nutritional status [29]. The GNDVI index is another vegetative spectral index related with the leaf properties such as the chlorophyll content [30]. The GNDVI differs from the NDVI in the fact that in the ratio calculation, the green band $(560 \mathrm{~nm})$ is used instead of the red band $(670 \mathrm{~nm})$. In season 2020, the NDVI spectral sensor (SRS, Meter Group Inc., Pullman, WA, USA) was used to reliably track the NDVI. The spectral reflectance sensor is a multiband radiometer that measures the Normalized Difference Vegetation Index and corrects the calculated indices with the incident illumination pattern by using an extra double-band sensor pointing at the sky. Their bands are centered at $650 \mathrm{~nm}$ and $810 \mathrm{~nm}$, with $50 \mathrm{~nm}$ and $40 \mathrm{~nm}$ full width half maximum (FWHM), respectively. This sensor also presented a FOV of $36^{\circ}$ (Figure 2a) and was embedded in the crop sensing unit of the robot (Figure 2b). 


\subsection{On-the-Go Measurements from the Ground Robot}

Grapevines were monitored at two different times of day: morning at 10:00 am, and midday at 14:00 pm (local time) on the 5th of September 2019, and the 7th of August in 2020.

In 2019, the infrared radiometer, the multispectral camera, and the environmental sensors were installed on the Vinescout robot. The multispectral camera and the infrared radiometer were placed in the robot at $1 \mathrm{~m}$ height from the ground, and at an approximate distance to the canopy of $0.5 \mathrm{~m}$, aiming at the central section of the canopy to avoid the influence of the sky and soil. For this target distance and field of view (FOV) of the camera and the infrared radiometer, the multispectral images covered scenes of approximately $0.35 \mathrm{~m}$ horizontally and $0.20 \mathrm{~m}$ vertically, while the measuring window (circle) of the infrared radiometer had a diameter of $0.33 \mathrm{~m}$. In the 2020 season, a new set of environmental sensors and a NDVI compact sensor were installed in the Vinescout robot (Figure 2b). In both seasons, on-the-go measurements were collected on the north side of the grapevine canopy at an average speed of $1.5 \mathrm{Km} \mathrm{h}^{-1}$. All field measurements were georeferenced using a GPS receiver (SX-Blue, Geneq Inc., Montreal, QC, Canada) installed on the robot (Figure 2a).

The multispectral camera presents several limitations, since embedded software includes proper functionality only for images taken from aerial vehicles. As a result, software was developed to match the images that corresponded to the same scene in different spectral bands. To avoid taking white reference images frequently in the vineyard, the algorithm adjusted the camera exposure time for each band in the image, preventing undesired oscillations in image exposure due to sudden changes in environmental lighting. White references from various light conditions were stored and chosen accordingly to the field conditions for each measuring day. The compact spectral reflectance sensor, on the contrary, executed ambient light corrections in real time, using the same spectral bands used for NDVI calculations ( $650 \mathrm{~nm}$ and $810 \mathrm{~nm}$ ) but oriented zenithally rather than at the canopy, and outputting the adjusted value for each measuring point.

In summary, the crop measuring cycle operated at $\sim 2 \mathrm{~Hz}$, and included the radiometric measurement of the canopy temperature at a distance of about $50 \mathrm{~cm}$ (this distance may slightly vary due to the irregularities of the terrain), the NDVI determined from the same distance and pointing at the same canopy spot, and the environmental measurement of air temperature, relative humidity and atmospheric pressure by a probe mounted $20 \mathrm{~cm}$ below the infrared radiometer as indicated in Figure 2b. Every measuring cycle ends in data recording to a text file; however, when the side ultrasonic sensors pointing at the canopy spot measured by the IR radiometer detected the absence of vegetation (canopy gap or headland turn), data points were not added to the text file. This filtering turned out to be very helpful to discard wrong temperature measurements and NDVI estimates not coming from the vineyard row being measured, as for example, neighboring rows. The ultrasonic sensor operated at frequencies much higher than the crop measuring cycle, and therefore their distance measurements were considered to be in real time.

\subsection{Leaf Water Potential $\left(\boldsymbol{\Psi}_{l}\right)$ as Reference Indicator of Grapevine Water Status}

Leaf water potential $\left(\Psi_{1}\right)$ was used as a reference indicator of the plant water status (ground truth), and its measurement was taken simultaneously to the vineyard monitoring by the robot. Leaf water potential has been widely used to discriminate among water treatments [31-34] as well as in many studies aimed at understanding the physiological behavior of grapevines against drought and water stress [35,36]. A Schölander pressure bomb (Model 600, PMS Instruments Co., Albany, NY, USA) was used to assess the leaf water potential $\left(\Psi_{1}\right)$ at two different periods during the day: morning (between 9:00 and 10:00 a.m.) and midday (between 14:00 and 15:00 local time). A total of 30 measuring units (Figure 1a) were evaluated in the morning and midday, in 2019, while 36 measuring units (Figure 1b) were monitored in 2020 at each timing. Each measuring unit comprised five plants. Of these, three plants were selected (one leaf per plant from the mid-upper part of 
the canopy) to measure the leaf water potential, making a total of 90 plants per day at each timing of the day in 2019 season and 108 plants in 2020 season. The three measurements of each measuring unit were averaged for each day and time of measuring.

\subsection{Data Analysis and Modeling}

Grapevines' canopy temperature $\left(T_{c}\right)$ values recorded with the infrared radiometer, as well as data acquired with the environmental sensor ( $T_{\text {air }}, \mathrm{RH}$, and AP) were automatically saved in the computer of the robot. In fact, the field measurements were shown in real time on the robot's screen as monitoring was occurring. The multispectral images (season 2019) and the NDVI measurements acquired with the spectral reflectance sensor (season 2020) were also recorded on the computer. As explained earlier, each measurement unit in the vineyard consisted of a group of five consecutive vines within the same block. Likewise, a unique averaged value of $T_{c}$, environmental variables and spectral vegetative indices was assigned to each group of five vines or measuring unit. The identification of each measuring unit was accomplished with the global positioning recorded by the GPS of the ground robot.

Calibration and prediction models for grapevine water status assessment were performed using the PLS Toolbox (version 8.1, Eigenvector Research, Inc., Manson, WA, USA) software in conjunction with MATLAB (version 2019a, The Mathworks Inc., Natick, MA, USA). Partial least squares (PLS) regression was used as the algorithm for training the plant water status prediction models using average water potential reference values $(Y$ matrix) and all the sensors' variables and vegetative indices ( $X$ matrix) retrieved from the moving vehicles from each measuring unit as inputs. The PLS regression is a quick, efficient and optimal regression method based on covariance that is recommended where the number of explanatory variables is high. In comparison to ordinary least squares regression and other multivariate methods (e.g., principal component regression), in PLS regression the covariance structure of the estimated variable is taken into account [37]. A K-fold cross-validation was conducted to choose the optimal number of latent variables (LV) as well as to obtain an estimation of the error rate of the models. To evaluate the quality of the models, the determination coefficient of calibration $\left(R^{2}\right)$ and cross-validation $\left(\mathrm{R}_{\mathrm{CV}}{ }\right)$, the root mean square error of calibration (RMSEC) and cross-validation (RMSECV) were calculated.

Analysis of variance among the different water regimes were conducted for separately for each day at each of the two timings (morning and midday). Post hoc mean comparisons for $\Psi_{1}$ were conducted using the Tukey test. ANOVA and mean comparison tests were carried out using Infostat (2014) software [38].

\subsection{Mapping Vineyard Water Status}

To illustrate the capability of the developed methodology to assess the vineyard water status variability, maps of the reference $\boldsymbol{\Psi}_{1}$ values obtained with the pressure chamber and maps of the predicted values of $\Psi_{1}$ with the autonomous robot for both seasons were generated using empirical Spline interpolation [39], implemented in ArcGis 10.3 (Environmental Systems Research Institute, Redlands, CA, USA). To explore the variability of the plants' water status, interpolation with no more than five classes was selected, to ease zone segmentation and decision making based on the map, while maintaining reasonable granularity.

\section{Results}

\subsection{Environment Data and Leaf Water Potential}

Table 2 summarizes the average of the air temperature, relative humidity and atmospheric pressure, plus the calculated vapor pressure deficit (VPD), making a distinction between morning and midday. As observed, increased air temperature, lower RH and atmospheric pressure, as well as higher values of VPD occurred during the midday time window as compared to the morning time. 
Table 2. Summary of the averaged values of the environmental variables measured from the on-board sensors during on-the-go measurements (morning: 10:00 a.m.; midday: 14:00 p.m.).

\begin{tabular}{ccc}
\hline \multirow{2}{*}{ Environmental Variable } & 5 September 2019 & 7 August 2020 \\
\cline { 2 - 3 } & Morning/Midday & Morning/Midday \\
\hline $\mathrm{T}_{\text {air }}\left({ }^{\circ} \mathrm{C}\right)$ & $25.4 / 31.6$ & $30.1 / 38.1$ \\
$\mathrm{RH}(\%)$ & $30.5 / 18.2$ & $43.2 / 25.2$ \\
$\mathrm{AP}(\mathrm{hPa})$ & $1006 / 1003$ & $998 / 996$ \\
$\mathrm{VPD}(\mathrm{kPa})$ & $2.26 / 3.81$ & $2.44 / 4.99$ \\
\hline
\end{tabular}

Table 3 shows the average values of $\Psi_{1}$ for the different irrigation regimes, measured at morning and midday in the two seasons. Significant differences among irrigation regimes were found at $p<0.01$ at the morning time in both seasons, while for midday, only in 2019 .

Table 3. Average values of leaf water potential $\left(\Psi_{1}\right)$ for the different irrigation regimes measured with the pressure chamber at morning (10:00 a.m.) and midday (14:00 p.m.). (Irrigation regimes: 15\%, $30 \%$ and $60 \%$ of crop reference $\mathrm{ET}_{\mathrm{C}}$ ).

\begin{tabular}{|c|c|c|c|c|}
\hline \multirow[b]{2}{*}{ Irrigation Regime } & \multicolumn{2}{|c|}{5 September 2019} & \multicolumn{2}{|c|}{7 August 2020} \\
\hline & $\begin{array}{l}\Psi_{1}(\mathrm{MPa}) \\
\text { Morning }\end{array}$ & $\begin{array}{l}\Psi_{1}(\mathrm{MPa}) \\
\text { Midday }\end{array}$ & $\begin{array}{l}\Psi_{1}(\mathrm{MPa}) \\
\text { Morning }\end{array}$ & $\begin{array}{l}\Psi_{1}(\mathrm{MPa}) \\
\text { Midday }\end{array}$ \\
\hline $15 \%$ & $-1.45 b$ & $-1.52 b$ & $-1.22 b$ & -1.51 \\
\hline $30 \%$ & $-1.20 b$ & $-1.44 \mathrm{a}$ & - & - \\
\hline $60 \%$ & $-1.08 \mathrm{a}$ & $-1.26 a$ & $-0.96 a$ & -1.46 \\
\hline Significance $p$-value & 0.001 & $<0.001$ & 0.004 & 0.351 \\
\hline
\end{tabular}

For $\Psi_{1}$, mean values (season 2019: $n=30$; season 2020: $n=54$ ) within columns were separated by the Tukey test $(p=0.05)$, where $\mathrm{a}$ and $\mathrm{b}$ indicate statistical outcomes.

As expected, irrigation regimes watering larger amounts of water (increased $\% \mathrm{ET}_{\mathrm{c}}$ ) led to higher $\Psi_{1}$ values (less negative) and these were found to decrease from morning to midday in both seasons. While the most extreme irrigation regimes $\left(15 \% \mathrm{ET}_{\mathrm{c}}\right.$ and $\left.60 \% \mathrm{ET}_{\mathrm{C}}\right)$ were significantly discriminated by $\boldsymbol{\Psi}_{1}$, the $\boldsymbol{\Psi}_{1}$ corresponding to the intermediate irrigation treatment $\left(30 \% \mathrm{ET}_{\mathrm{C}}\right)$ was not significantly discriminated from $15 \% \mathrm{ET}_{\mathrm{C}}$ in the morning and from $60 \% \mathrm{ET}_{\mathrm{c}}$ in the midday, in season 2019 (Table 3).

\subsection{Predictive Models for Vineyard Waters Status}

The direct regression between the average canopy temperature $\left(T_{c}\right)$ and the leaf water potential $\left(\Psi_{1}\right)$ for each measuring unit yielded coefficients of determination $\left(R^{2}\right)$ lower than 0.30 in the two seasons, at the two timings of the day (Table 4). In terms of the standard error of estimation (SEE) values, these ranged from 0.15 to $0.25 \mathrm{MPa}$.

Table 4. Determination coefficients $\left(\mathrm{R}^{2}\right)$ and standard errors (SEE) of the linear regressions between the average canopy temperature and leaf $\left(\Psi_{1}\right)$ water potential in both seasons (regression was conducted per measuring unit).

\begin{tabular}{ccccccc}
\hline \multirow{2}{*}{ Timing } & \multicolumn{3}{c}{ Season 2019 } & \multicolumn{4}{c}{ Season 2020 } \\
\cline { 2 - 7 } & $\boldsymbol{n}$ & $\mathbf{R}^{\mathbf{2}}$ & SEE (MPa) & $\boldsymbol{n}$ & $\mathbf{R}^{\mathbf{2}}$ & SEE (MPa) \\
\hline Morning & 30 & 0.222 & 0.185 & 36 & 0.298 & 0.246 \\
Midday & 30 & 0.129 & 0.171 & 36 & 0.096 & 0.153 \\
\hline
\end{tabular}

As the performance indicators of the direct regressions between the plant's temperature and its water potential were low, a multivariate regression approach was attempted. Table 5 summarizes the variables involved in the models for the two seasons. 
Table 5. Variables included in the PLS models for 2019 and 2020 seasons. Average canopy temperature $\left(\mathrm{T}_{\mathrm{c}}\right)$; air temperature $\left(\mathrm{T}_{\text {air }}\right)$; relative humidity $(\mathrm{RH})$; atmospheric pressure $(\mathrm{AP})$; vapor pressure deficit (VPD); normalized difference vegetation index (NDVI); green normalized difference vegetation index (GNDVI).

\begin{tabular}{cc}
\hline & Variables \\
\hline Season 2019 & Season 2020 \\
\hline $\mathrm{T}_{\mathrm{c}}\left({ }^{\circ} \mathrm{C}\right)$ & $\mathrm{T}_{\mathrm{c}}\left({ }^{\circ} \mathrm{C}\right)$ \\
$\mathrm{T}_{\text {air }}\left({ }^{\circ} \mathrm{C}\right)$ & $\mathrm{T}_{\text {air }}\left({ }^{\circ} \mathrm{C}\right)$ \\
$\mathrm{RH}(\%)$ & $\mathrm{RH}(\%)$ \\
$\mathrm{AP}(\mathrm{hPa})$ & $\mathrm{AP}(\mathrm{hPa})$ \\
$\mathrm{VPD}(\mathrm{kPa})$ & $\mathrm{VPD}(\mathrm{kPa})$ \\
$\mathrm{T}_{\mathrm{c}}-\mathrm{T}_{\text {air }}$ & $\mathrm{T}_{\mathrm{c}}-\mathrm{T}_{\text {air }}$ \\
$\mathrm{NDVI}$ & $\mathrm{NDVI}$ \\
GNDVI & - \\
Chlorophyll Band 560 & - \\
HydricStress Band 840 & -
\end{tabular}

When the data acquired in the morning were considered (Figure 4 ), the $\mathrm{R}_{\mathrm{c}}^{2}$ of the multivariate model was $\sim 0.67$ in both seasons, while the $\mathrm{R}_{\text {cv }}{ }_{\text {was }} 0.45$ in 2019 (Figure 4a) and 0.57 in 2020 (Figure $4 \mathrm{~b}$ ). In terms of the RMSEC and RMSECV, these ranged from $0.152 \mathrm{MPa}$ to $0.190 \mathrm{MPa}$.

Equations (1) and (2) of PLS models for leaf water potential at morning during 2019 and 2020 seasons are reported as:

$$
\begin{gathered}
\mathrm{Y}=-441.3+0.018 \cdot \mathrm{T}_{\mathrm{c}}+0.108 \cdot \mathrm{T}_{\text {air }}+0.059 \cdot \mathrm{RH}+0.433 \cdot \mathrm{AP}+0.160 \cdot \mathrm{VPD}- \\
0.905 \cdot \mathrm{NDVI}+0.352 \cdot \mathrm{GNDVI}-1.465 \cdot \text { Chlorophyll Band } 560-0.273 \cdot \\
\text { HydricStress Band } 840-0.030 \cdot\left(\mathrm{T}_{\mathrm{c}}-\mathrm{T}_{\text {air }}\right) \\
\mathrm{Y}=-1.458-0.031 \cdot \mathrm{T}_{\mathrm{c}}+0.004 \cdot \mathrm{T}_{\text {air }}-0.008 \cdot \mathrm{RH}+0.0001 \cdot \mathrm{AP}+0.177 \cdot \mathrm{VPD}+ \\
2.351 \cdot \mathrm{NDVI}-0.130 \cdot\left(\mathrm{T}_{\mathrm{c}}-\mathrm{T}_{\text {air }}\right)
\end{gathered}
$$

As for the data acquired in the midday (Figure 5), lower values of $R^{2}{ }_{c}(0.50-0.63)$ and $\mathrm{R}^{2}{ }_{\mathrm{cv}}(\sim 0.40)$ than those of the morning models were obtained. Regarding the RMSEC and RMSECV, these were also smaller than those yielded by the morning models, and the RMSECV was $0.141 \mathrm{MPa}$ in 2019 (Figure 5a) and 0.125 in 2020 (Figure 5b). The models obtained in the midday also had a lower number of latent variables (three) than the morning models (four latent variables). At the two timings, adequate data dispersion was observed and all data except one point in each PLS model laid within the 95\% confidence bands. For the morning timing, $\Psi_{1}$ ranged from -0.60 to $-1.68 \mathrm{MPa}$ (Figure 4), while for the midday timing $\Psi_{1}$ ranged from -1.00 to $-1.70 \mathrm{MPa}$ (Figure 5), which accounted for grapevines showing weak $\left(-0.9>\Psi_{1}>-1.1 \mathrm{MPa}\right)$, moderate $\left(-1.1>\Psi_{1}>-1.4 \mathrm{MPa}\right)$ and severe $\left(\Psi_{1}<-1.4 \mathrm{MPa}\right)$ water stress [40]. 

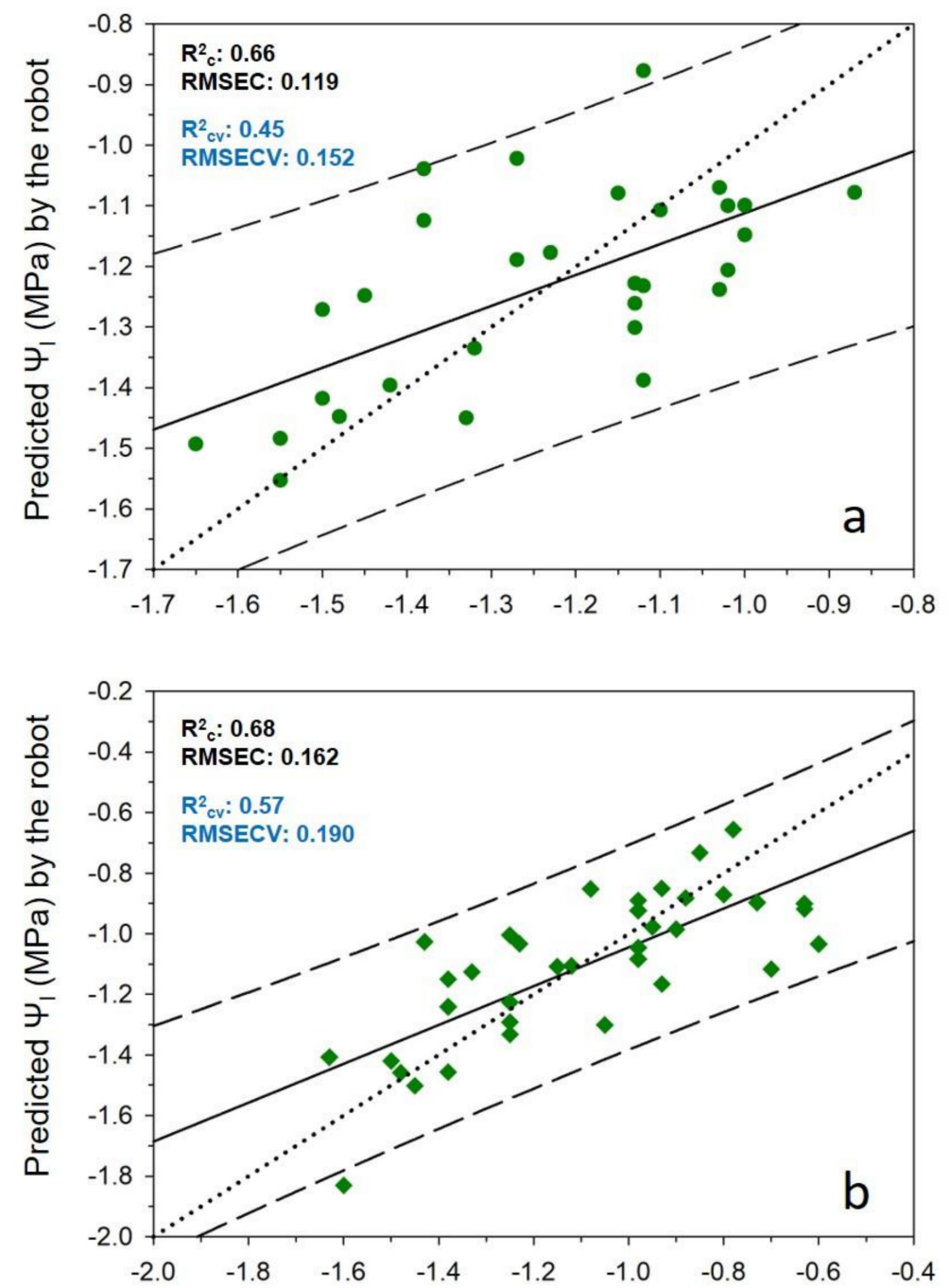

Measured $\Psi_{1}(\mathrm{MPa})$ by pressure chamber

Figure 4. The best PLS prediction models for plant water status at morning during 2019 season (a), and 2020 (b). Solid lines represent the regression line and dotted line refers to the 1:1 line. Prediction confidence bands are shown at a 95\% level (dashed lines).

Equations (3) and (4) of the PLS models for leaf water potential in the midday during the 2019 and 2020 seasons, respectively, are reported as:

$$
\begin{gathered}
\mathrm{Y}=43.82-0.035 \cdot \mathrm{T}_{\mathrm{c}}-0.049 \cdot \mathrm{T}_{\text {air }}+0.036 \cdot \mathrm{RH}-0.042 \cdot \mathrm{AP}+0.177 \cdot \mathrm{VPD}- \\
1.300 \cdot \mathrm{NDVI}+0.843 \cdot \mathrm{GNDVI}-1.184 \cdot \mathrm{Chlorophyll} \text { Band } 560+0.396 \cdot \\
\text { HydricStress Band } 840-0.019 \cdot\left(\mathrm{T}_{\mathrm{c}}-\mathrm{T}_{\text {air }}\right) \\
\mathrm{Y}=-280.071-0.001 \cdot \mathrm{T}_{\mathrm{c}}+0.135 \cdot \mathrm{T}_{\text {air }}+0.102 \cdot \mathrm{RH}+0.271 \cdot \mathrm{AP}+0.169 \cdot \mathrm{VPD}+ \\
0.536 \cdot \mathrm{NDVI}-0.005 \cdot\left(\mathrm{T}_{\mathrm{c}}-\mathrm{T}_{\text {air }}\right)
\end{gathered}
$$



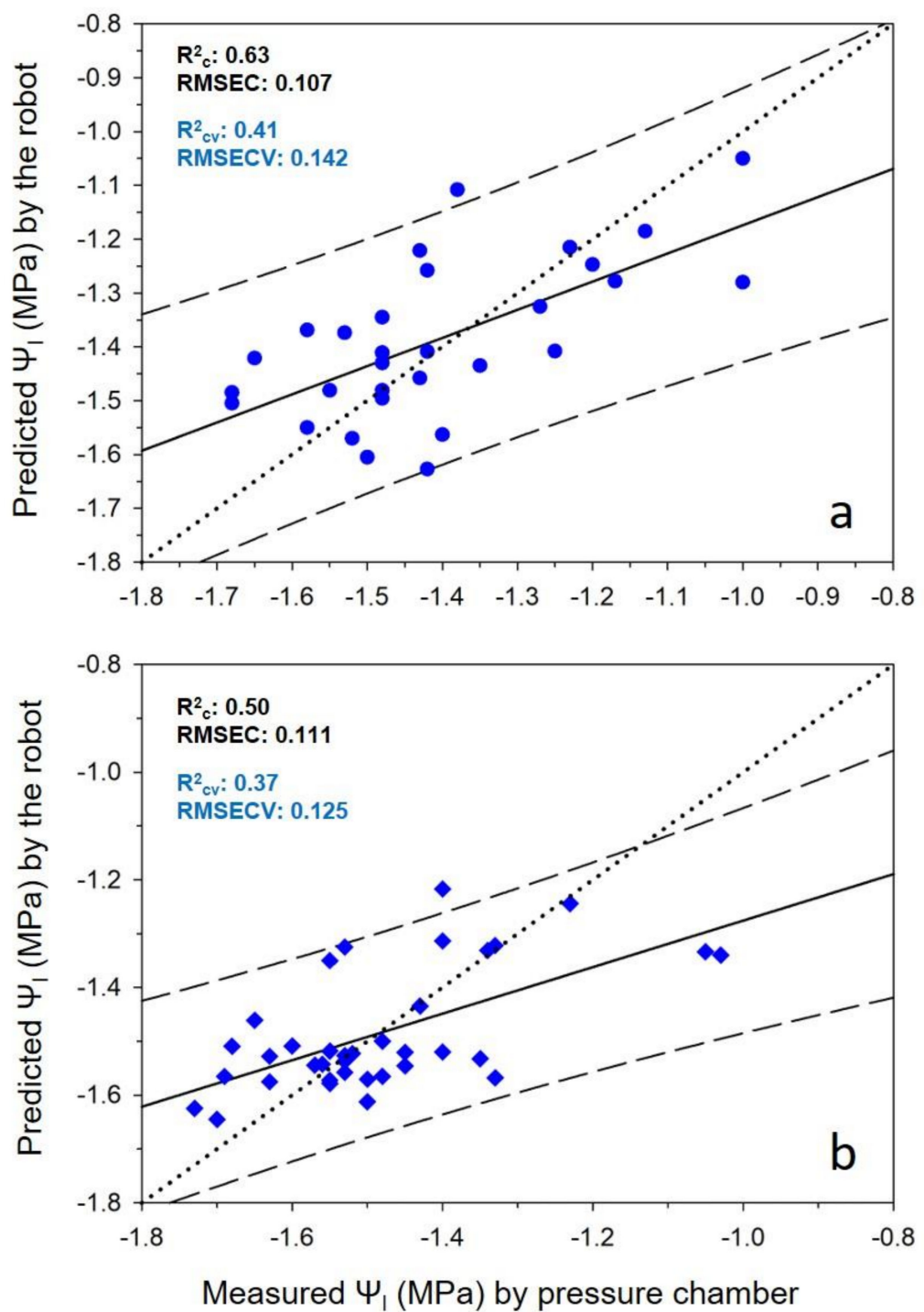

Figure 5. The best PLS prediction models for plant water status in the midday during 2019 (a) and 2020 (b). The solid line represents the regression line and dotted line refers to the 1:1 line. Prediction confidence bands are shown at a 95\% level with dashed lines.

\subsection{Mapping Vineyard Waters Status Variability}

To analyze the spatial variability of the vineyard water status, maps of the reference $\boldsymbol{\Psi}_{1}$ values obtained with the pressure chamber, and maps of estimated $\Psi_{1}$ using the PLS model (Equations (1)-(4)) built from the data gathered with the sensors installed in the robot were prepared for the two-timing periods in season 2019 (Figure 6) and 2020 (Figure 7).

The spatial variability of the measured (manual) and estimated (robot) $\Psi_{1}$ in the morning (Figure 6a,c) and midday (Figure 6b,d) shows a similar distribution, which matches the different irrigation treatments established in 2019 (Figure 1a). Nevertheless, the highly stressed area corresponding to the $15 \% \mathrm{ET}_{\mathrm{c}}$ in the middle of the plot (Rows 8 and 16 in Figure 1a) was more intensely highlighted in the midday maps (Figure 6b,d) than in the morning ones (Figure $6 a, c)$.

In 2020 , when only the $15 \% \mathrm{ET}_{\mathrm{c}}$ and $60 \% \mathrm{ET}_{\mathrm{c}}$ irrigation treatments were imposed, the spatial distribution of the grapevine water potential, both measured (Figure 7a,b) and estimated from the on-the-go measurements with the robot (Figure 7c,d), was less coherent with the irrigation treatments applied in the vineyard plot, and seemed more affected by differences in soil and plant vigor along the rows (Figure 1b). Comparing the maps for the two timings, larger areas of the vineyard corresponded to the orange and red classes 
(representing highly stressed vines with $\Psi_{1}<-1.4 \mathrm{MPa}$ ) in the midday maps (Figure $7 \mathrm{~b}, \mathrm{~d}$ ). In both seasons, a shift from green classes (less stressed) in morning maps, towards yellow or even orange classes (increased water stress) in midday maps was also observed.

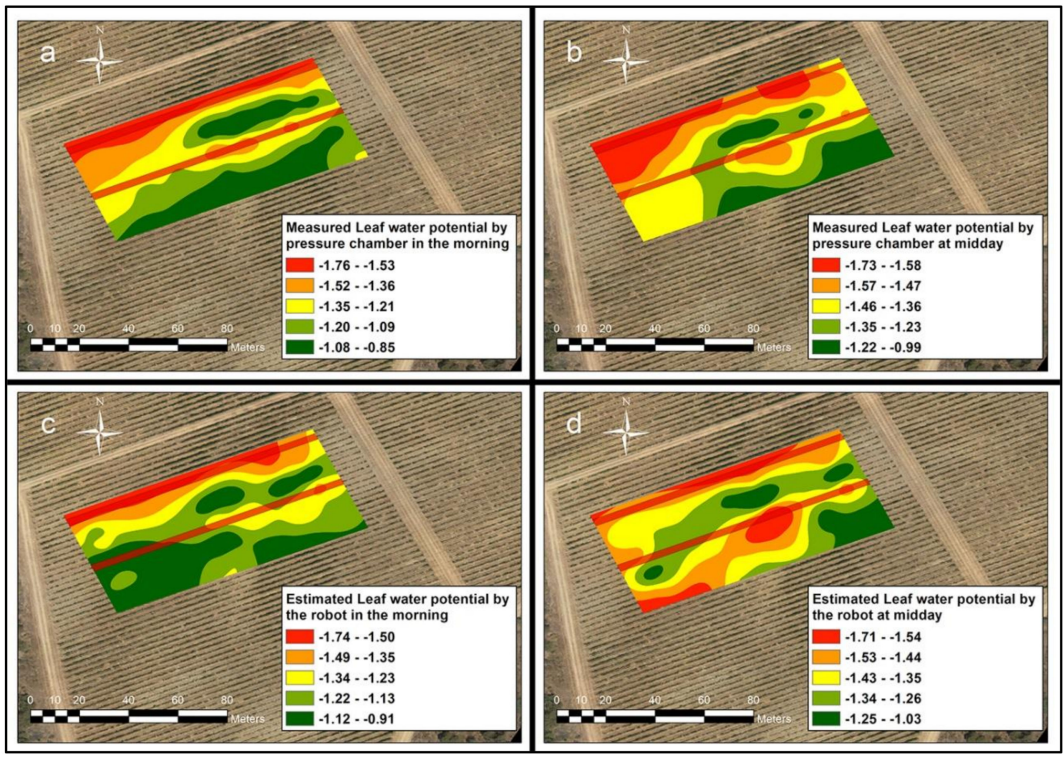

Figure 6. Maps of leaf water potential for season 2019. (a) Measured $\Psi_{1}$ in the morning; (b) measured $\Psi_{1}$ in the midday; (c) estimated $\Psi_{1}$ by the robot in the morning; (d) estimated $\Psi_{1}$ by the robot in the midday. Red solid lines represent the lowest irrigation treatments $\left(15 \% \mathrm{ET}_{\mathrm{c}}\right)$.

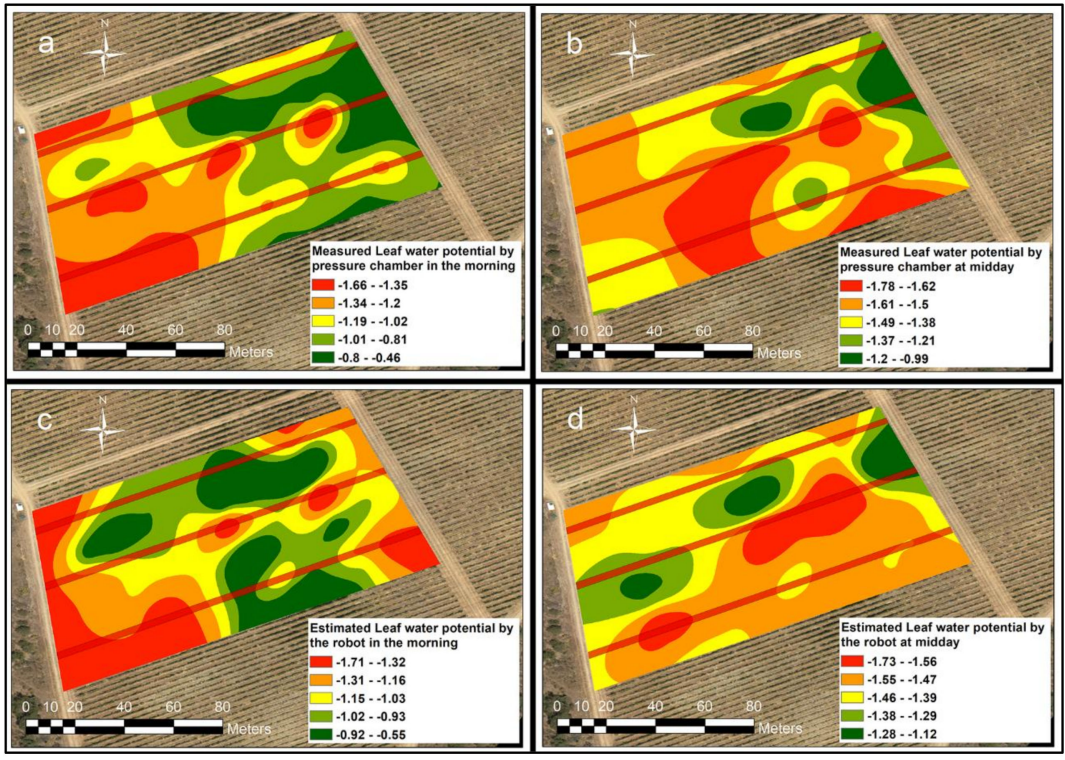

Figure 7. Maps of leaf water potential for season 2020. (a) Measured $\Psi_{1}$ in the morning; (b) measured $\Psi_{1}$ in the midday; (c) estimated $\Psi_{1}$ by the robot in the morning; (d) estimated $\Psi_{1}$ by the robot in the midday. Red solid lines represent the lowest irrigation treatments $\left(15 \% \mathrm{ET}_{\mathrm{C}}\right)$.

\section{Discussion}

Precision irrigation [41] and the use of variable rate irrigation [42] are two of the potential techniques suitable for increasing water use efficiency in viticulture. However, the successful implementation of these strategies requires the previous understanding of the vineyard heterogeneity. Current trends in the primary sector include incorporating agricultural robotics and automated equipment to monitor crops and perform precision 
agriculture, or viticulture in the case of vines. This data-driven agriculture can make use of sensed data to optimize inputs according to the particular needs [43].

This study presents the Vinescout robot prototype for the assessment of the vineyard water status variability, its sensing system and the developed methodology behind the automated monitoring and mapping. This achievement constitutes an advance from existing solutions to assess plant water status variability and zone delineation for irrigation management in three main ways: (a) the capability of automated monitoring the vineyard water status from an autonomous ground vehicle, (b) the simplicity and automation potential of the IR radiometer employed at no expense of decreasing its performance compared to thermal cameras, and (c) the integration of environmental and canopy-related data into the model for the non-invasive estimation of the grapevine water status

The estimation of plant water status with this new approach was automated with the introduction of a monitoring robot (neither human intervention for data acquisition nor vehicle driving), and the outcomes of the present work are relevant and coherent to the statement of Maes and Steppe [20], who called for automation of thermography prior to its use at field scale in agricultural practice. One of the main advantages of the VineScout approach to assess plant water status is that vineyard water status variability can be mapped, expanding the concept and application of precision viticulture, in this case, precision irrigation or variable rate irrigation, to optimize water usage and efficiency. In grapevines, canopy vigor and plant water status interactions significantly affect yield, fruit composition and wine parameters. For this reason, site-specific management of irrigation may successfully regulate and influence yield and fruit composition within a block [44]. If maps can be obtained from an autonomous robot, such as VineScout, in real time, or immediately after finishing field monitoring, the advantages of the presented approach become even more relevant, as decision making regarding precise irrigation can be taken promptly with no delay between monitoring and actuation. This is made possible by leveraging the complexity of the sensors involved in the data acquisition process, and by automating data collection and modeling in the robot internal computer. The approach presented in this work goes beyond the use of an autonomous ground vehicle as a mere sensor-carrying platform, as full, automated processing of acquired data and map building featuring zone delineation are performed as well. While the low navigation speed $(1.5 \mathrm{~km} / \mathrm{h})$ may be seen as a limitation for water status monitoring in large vineyard plots, depending on the extent of soil variation within the plot, monitoring at every other row or at a selected number of representative rows can reduce the mission time significantly. Low speed, conversely, implies a richer resolution for the water status maps at the same cost, since the platform moves autonomously. Nevertheless, further research and testing is currently undergoing to increase the navigation speed to $3 \mathrm{~km} / \mathrm{h}$. Compared to aerial alternatives (i.e., Drones), these can cover larger vineyard areas in shorter times, but their mission time does not usually exceed $20 \mathrm{~min}$ (limited by their battery duration) in comparison to the extended operation time of up to four hours, granted by the VineSocut robot. Additionally, drones cannot be operated under moderate to strong wind conditions or in certain areas close to commercial airports and other Government facilities, and often require specific permissions to operate.

Most of the research conducted on thermography applied to plant water status assessment, in viticulture and other crops, has used thermal cameras of lower [15] or higher resolution [17], portable thermal devices [45], and cameras mounted on ground [18] or aerial platforms [46,47]. However, image processing is a time-consuming step that requires expert knowledge in both software and thermography [20]. For this reason, the few methods currently applied in agriculture for drought stress detection and irrigation management, make use of infrared thermal sensors (also called infrared radiometers), installed on static poles or moving pivots, rather than cameras [20]. Likewise, crop canopy temperature measured with infrared radiometers has been successfully used to monitor plant water stress $[48,49]$ and, using specific algorithms, to control irrigation scheduling as well $[50,51]$. These sensors provide an average value of the surface temperature of the 
target (in this case the grapevine canopy) at a given time frequency. In this work one of these infrared thermal sensors was installed in the VineScout robot and used to monitor the grapevine canopy temperature on the go, and canopy temperature values were recorded (almost two measurements per second) and sent to the internal computer of the robot. The automated measurement of canopy temperature in real time without the need for image processing [19] enabled the practical and efficient monitoring of grapevine canopy temperature along the vineyard without using the physically demanding pressure cameras. However, the relationship between the recorded canopy temperature and the plant water status (using grapevine leaf water potential) was not straightforward, as shown by the low determination coefficients obtained in seasons 2019 and 2020. Weak relationships between canopy temperature and plant water potential were also found in almond [52] and cherry trees [14] while other authors have reported better performance in grapevines [17]. This outcome was expected for the following reasons. Leaf temperature is well known to be linearly related to evapotranspiration, but largely influenced by the microclimatic conditions and their changes such as air temperature, wind speed, or radiation [20,21]. For this reason, a mathematical normalization of leaf or canopy temperature is required for most applications, being the most common the use of reference values of $\mathrm{T}_{\mathrm{dry}}$ and $\mathrm{T}_{\text {wet, }}$ that are used to compute the widely known thermal indices Crop Water Stress Index (CWSI) [53] and Conductance Index [54]. Nevertheless, the use of reference temperatures is not practical for on-the-go applications, as both $\mathrm{T}_{\mathrm{dry}}$ and $\mathrm{T}_{\text {wet }}$ should ideally be recorded at the same time as canopy temperature. Although several approaches to defining these reference temperatures have been postulated $[10,45,55]$, the use of reference temperatures still remains an important barrier towards the automated use of thermography [18]. To avoid the use of reference temperatures, but with the aim of including environmental information to "correct" canopy temperature, sensors recording the environmental variables (air temperature, relative humidity and atmospheric pressure) were installed close-between $40 \mathrm{~cm}$ and $70 \mathrm{~cm}$ - to the targeted canopy, and their information, which was captured simultaneously to the canopy temperature, was used to build a multivariate predictive model. In addition, with the aim of reinforcing the prediction model with data related to the vegetative status of the canopy and its variability, spectral information gathered on-the-go and simultaneously to the canopy temperature was also included in the model (Equations (1)-(4)).

The results obtained in the present work are in good agreement with previous works carried out on the go (ground-based) and from aerial platforms. Regarding the former, a previous study carried out on the go, from an all-terrain vehicle (ATV) in which a thermal camera was embedded [18], reported $R^{2}=0.65$ and RMSE $=0.184 \mathrm{MPa}$ between the predicted and observed stem water potential $\left(\Psi_{\mathrm{S}}\right)$, which was used as plant water status indicator. In comparison to airborne thermography, acquired from a drone, when estimated vs. measured values of leaf water potential of a 16 ha commercial vineyard of Chardonnay were correlated [56] (Bellvert et al., 2016), $\mathrm{R}^{2}$ ranged from 0.31 (when all dates from anthesis to post-harvest were included) to 0.61 (when only data from dates between fruitset and harvest with VPD above $2.3 \mathrm{kPa}$ were considered), and the corresponding RMSEs for these two models were 0.21 and 0.15 MPa, respectively. In another work [10] (Cohen et al., 2017), aerial thermography, using a thermal camera mounted on a manned airplane, was used to assess the leaf water potential in cotton fields over several seasons. The relationships between the estimated vs. measured values of $\Psi_{1}$ yielded $\mathrm{R}^{2}$ values ranging from 0.32 to 0.88 , with RMSE varying from 0.12 to $0.22 \mathrm{MPa}$ depending on the approach used to compute the $\mathrm{T}_{\mathrm{dry}}$ and $\mathrm{T}_{\text {wet }}$ references. Likewise, plant water potential can be estimated with similar degree of correlation and uncertainty using canopy thermal measurements acquired either from ground-based or aerial platforms, but the simplicity of the measurement (using an infrared radiometer vs. a thermal camera) and automation, provided by the VineScout robot are two factors contributing to the effective application of this technology for vineyard water status assessment in commercial vineyards. 
Two factors may have influenced the performance indicators $\left(\mathrm{R}_{\mathrm{CV}}{ }_{\mathrm{c}}\right.$ and RMSECV) of the estimation of the plant water potential from the canopy temperature alone (direct relationship) versus the estimation using ancillary data (multivariate predictive model): (a) the differences between leaf temperature [57] and canopy temperature (which is the one recorded with the infrared radiometer), and (b) the differential sensitivity of plant water potential to changes in water availability in the soil. Regarding the differences between leaf and canopy temperature, Maes and Steppe [20] reported that these two can vary with several degrees within and between plants, as a consequence of differences in leaf angle, dimension and emissivity within a canopy, as well as from the fact that canopy temperature is a composite of surface temperature of different materials, including leaves, gaps and wood. In this work, the infrared radiometer model (FOV 61.9 $\left.(\mathrm{H}) \times 48.5^{\circ}(\mathrm{V})\right)$ and its position in the robot relative to the canopy were chosen to have a measuring window of $0.33 \mathrm{~m}$ of diameter, being a trade-off between the representativeness of the measured area, and minimizing the presence of objects other than leaves (e.g., gaps or wood) in the measuring spot. This could certainly have influenced the average value of the canopy temperature recorded by the infrared radiometer, as it averaged the temperature data in the measuring window, whose variability will be higher when the grapevine becomes more water stressed [58].

On the other hand, leaf temperature is closely linked to the stomatal conductance (hence stomatal regulation). However, different response to water deficit between stomata regulation and plant hydraulics can be found among grapevine cultivars [59], and this may cause divergences in the behavior of plant temperature versus plant water potential. In this regard, stomatal conductance has been reported to be better estimated from thermal information (CWSI) than plant water potential in grapevines $[47,60]$ and olive trees [61].

Concerning the time of measurement, slightly better results were found for the morning models in both seasons in terms of $\mathrm{R}^{2}{ }_{\mathrm{cV}}$, but substantially lower values of RMSECV were observed for the midday models $(0.125-0.142 \mathrm{MPa})$. Similar findings were obtained by Alchanatis et al. [62], who found lower standard errors of estimated leaf water potential from CWSI in cotton in the midday as compared to morning measurements. In general, in the midday, more negative values of leaf water potential were measured, particularly for the less stressed plants (those corresponding to the $30 \%$ and $60 \% \mathrm{ET}_{\mathrm{c}}$ treatments) in both seasons, than during the morning time, indicating that the maximum expression of plant water stress was detected in the midday. This was also reflected in the shift from green zones (Figures 6a and 7a) towards increased areas corresponding to the yellow-orange-red classes (of higher water stress) in midday maps (Figures $6 \mathrm{~b}$ and $7 \mathrm{~b}$ ) of the variability of leaf water potential. However, this is not a result of the thermography usage and modeling, but of the intrinsic hydraulic regulation of the Touriga Nacional grapevines, as the measured (manual) and estimated (using the robot) maps coincide for the two measuring timings, morning and midday, respectively. A recent work [45] that investigated the best time of the day to estimate stomatal conductance for two Portuguese cultivars, Aragonez and Touriga Nacional, based on thermography concluded that the most adequate time frame during the day to monitor grapevine water status in Touriga Nacional was between 14 and $17 \mathrm{~h}$, as the highest significant differences in canopy temperature and stomatal conductance were found in this period.

The inclusion of vegetative spectral indices (such as the NDVI) in the VineScout prediction models of grapevine water status may have provided real-time feedback on grapevine water use from actual vegetative growth and abiotic or biotic stress patterns. Furthermore, NDVI is linearly related to canopy growth [24], and canopy growth has been shown to be a key factor determining grapevine water use [25]. Regarding the environmental variables, its contribution to the estimation of plant water status has also been highlighted by other authors. Petrie et al. [15] found that PLS regression models to estimate stomatal conductance and $\Psi_{\mathrm{S}}$ from canopy thermal information and several environmental variables (air temperature, $\mathrm{RH}$, solar radiation and wind speed) were weak, but most of the weather parameters made statistically significant contributions to 
the models, with special attention to wind speed, which was found to be the strongest contributor. Canopy temperature has long been recognized to change dramatically with wind [20], therefore the inclusion of a wind speed sensor for future trials should be encouraged as a potentially influential environmental variable, that could lead to improved estimations of the $\Psi_{1}$ using this multivariate approach based on on-the-go thermography with the VineScout.

Finally, the use of an autonomous robot like the Vinescout, presented in this work, able to move from one row to the other autonomously (URL: https://doi.org/10.528 1/zenodo.4719849, accessed on 26 April 2021), avoids human intervention in the field under harsh environmental conditions as midday heat in summer time in arid climates, or dangerous situations as steep vineyards. Additionally, as the Vinescout is electrically powered instead of being propelled with fossil fuel, the envisioned solution also contributes towards sustainable vineyard monitoring.

\section{Conclusions}

The results presented in this work show the great potential of vineyard monitoring from autonomous ground vehicles, like the VineScout, using several non-destructive technologies, such as thermography, multispectral imaging and a suite of environmental sensors for the estimation of water status in commercials vineyards. The article presents a novel agricultural robot to assess the vineyard water status variability and proposes a methodology for the mapping and delineation of homogeneous water status zones, with the purpose of helping in decision making regarding precise variable rate irrigation as a way to increase water use efficiency, wine-making sustainability, and yield quality. The implementation of these sensing technologies on vineyard robots, in which massive data acquisition with non-invasive sensors, plant modeling, and map construction are automated is a big step forward in precise vineyard monitoring, which additionally increases work efficiency by extending the working hours the machine is mapping while reducing risks for the operators who do not need to stand under unbearable climatic conditions any longer.

However, further studies involving additional environmental variables like wind speed or solar radiation in the VineScout robot, which have been recognized to affect plant water status, different grapevine cultivars, seasons, and locations should be conducted with the goal of improving the accuracy and robustness of the VineScout predictive models, so that these could become commercial, and used by any grower regardless vineyard location, altitude, latitude, or grape variety.

Supplementary Materials: The following are available online at https:/ /www.mdpi.com/article/10 $.3390 / \mathrm{rs} 13142830 / \mathrm{s} 1$, Figure S1: (a) RGB image showing the measured area gathered by the Infrared radiometer SI-421, and the infrared thermal image acquired by the ThermaCAM Flir P640 with its selected area (white line) in the grapevine canopy (b), Table S1: Statistical analysis for the Canopy temperature $\left(T_{c}\right)$ using the point low-cost sensor (Infrared radiometer SI-421) and the Infrared camera ThermaCAM Flir P640, Table S2: Statistical significance for the Canopy temperature $\left(\mathrm{T}_{\mathrm{c}}\right)$, obtained by Analysis of Variance facing the two thermal sensors.

Author Contributions: Conceptualization, J.F.-N., F.R.-M., F.S.A., J.T. and M.P.D.; Data curation, J.F.-N. and I.B.; Formal analysis, J.F.-N. and I.B.; Funding acquisition, F.R.-M.; Investigation, J.F.-N., I.B., F.S.A., J.V., J.T. and M.P.D.; Methodology, J.F.-N., F.R.-M., F.S.A., J.V., J.T. and M.P.D.; Project administration, V.S.-R.; Resources, A.C.-C.; Software, V.S.-R., I.B., F.R.-M. and A.C.-C.; Supervision, J.T. and M.P.D.; Validation, J.F.-N. and M.P.D.; Writing—original draft, J.F.-N.; Writing—review \& editing, V.S.-R., I.B., F.R.-M., A.C.-C., F.S.A., J.V., J.T. and M.P.D. All authors have read and agreed to the published version of the manuscript.

Funding: This research was funded by the European Union under grant agreement number 737669 (Vinescout project). 
Data Availability Statement: Publicly archived datasets generated during the research study can be found in the following URL: https:/ / doi.org/10.5281/zenodo.4555350, accessed on 22 February 2021.

Acknowledgments: The authors want to thank Symington Family Estates (Quinta do Ataide) for providing the technical support and the vineyard to carry out this study.

Conflicts of Interest: The authors declare no conflict of interest.

\section{References}

1. Vougioukas, S.G. Agricultural robotics. Annu. Rev. Control. Robot. Auton. Syst. 2019, 2, 365-392. [CrossRef]

2. Saiz-Rubio, V.; Rovira-Más, F. From smart farming towards agriculture 5.0: A review on crop data management. Agronomy 2020, 10, 207. [CrossRef]

3. Diago, M.P.; Tardaguila, J. Vinerobot: On-the-go vineyard monitoring with non-invasive sensors. In Proceedings of the 19th Meeting of the Group of International Experts of Vitivinicultural Systems for CoOperation (GiESCO), Pech Rouge-Montpellier, France, 31 May-5 June 2015.

4. Lopes, C.M.; Graça, J.; Sastre, J.; Reyes, M.; Guzmán, R.; Braga, R.; Monteiro, A.; Pinto, P.A. Vineyard yield estimation by VINBOT robot-preliminary results with the white variety Viosinho. In Proceedings of the 11th International Terroir Congress, McMinnville, OR, USA, 10-14 July 2016; pp. 458-463.

5. Rose, J.C.; Kicherer, A.; Wieland, M.; Klingbeil, L.; Töpfer, R.; Kuhlmann, H. Towards automated large-scale 3D phenotyping of vineyards under field conditions. Sensors 2016, 16, 2136. [CrossRef] [PubMed]

6. Roure, F.; Moreno, G.; Soler, M.; Faconti, D.; Serrano, D.; Astolfi, P.; Bardaro, G.; Gabrielli, A.; Bascetta, L.; Matteucci, M. GRAPE: Ground Robot for vineyArd Monitoring and ProtEction. In Proceedings of the Iberian Robotics Conference, Seville, Spain, 22-24 November 2017; pp. 249-260.

7. Bramley, R.G.V.; Hamilton, R.P. Understanding variability in winegrape production systems: 1 . Within vineyard variation in yield over several vintages. Aust. J. Grape Wine Res. 2004, 10, 32-45. [CrossRef]

8. Bramley, R.G.V. Understanding variability in winegrape production systems 2 . Within vineyard variation in quality over several vintages. Aust. J. Grape Wine Res. 2005, 11, 33-42. [CrossRef]

9. Acevedo-Opazo, C.; Ortega-Farias, S.; Fuentes, S. Effects of grapevine (Vitis vinifera L.) water status on water consumption, vegetative growth and grape quality: An irrigation scheduling application to achieve regulated deficit irrigation. Agric. Water Manag. 2010, 97, 956-964. [CrossRef]

10. Cohen, Y.; Alchanatis, V.; Saranga, Y.; Rosenberg, O.; Sela, E.; Bosak, A. Mapping water status based on aerial thermal imagery: Comparison of methodologies for upscaling from a single leaf to commercial fields. Precis. Agric. 2017, 18, 801-822. [CrossRef]

11. Jones, H.G. Irrigation scheduling: Advantages and pitfalls of plant-based methods. J. Exp. Bot. 2004, 55, 2427-2436. [CrossRef] [PubMed]

12. Acevedo-Opazo, C.; Tisseyre, B.; Guillaume, S.; Ojeda, H. The potential of high spatial resolution information to define withinvineyard zones related to vine water status. Precis. Agric. 2008, 9, 285-302. [CrossRef]

13. Jones, H.G.; Stoll, M.; Santos, T.; De Sousa, C.; Chaves, M.M.; Grant, O.M. Use of infrared thermography for monitoring stomatal closure in the field: Application to grapevine. J. Exp. Bot. 2002, 53, 2249-2260. [CrossRef] [PubMed]

14. Carrasco-Benavides, M.; Antunez-Quilobrán, J.; Baffico-Hernández, A.; Ávila-Sánchez, C.; Ortega-Farías, S.; Espinoza, S.; Gajardo, J.; Mora, M.; Fuentes, S. Performance Assessment of Thermal Infrared Cameras of Different Resolutions to Estimate Tree Water Status from Two Cherry Cultivars: An Alternative to Midday Stem Water Potential and Stomatal Conductance. Sensors 2020, 20, 3596. [CrossRef] [PubMed]

15. Petrie, P.R.; Wang, Y.; Liu, S.; Lam, S.; Whitty, M.A.; Skewes, M.A. The accuracy and utility of a low cost thermal camera and smartphone-based system to assess grapevine water status. Biosyst. Eng. 2019, 179, 126-139. [CrossRef]

16. Baluja, J.; Diago, M.P.; Balda, P.; Zorer, R.; Meggio, F.; Morales, F.; Tardaguila, J. Assessment of vineyard water status variability by thermal and multispectral imagery using an unmanned aerial vehicle (UAV). Irrig. Sci. 2012, 30, 511-522. [CrossRef]

17. Costa, J.M.; Egipto, R.; Sánchez-Virosta, A.; Lopes, C.M.; Chaves, M.M. Canopy and soil thermal patterns to support water and heat stress management in vineyards. Agric. Water Manag. 2019, 216, 484-496. [CrossRef]

18. Gutiérrez, S.; Diago, M.P.; Fernández-Novales, J.; Tardaguila, J. Vineyard water status assessment using on-the-go thermal imaging and machine learning. PLoS ONE 2018, 13, e0192037. [CrossRef] [PubMed]

19. Liu, M.; Guan, H.; Ma, X.; Yu, S.; Liu, G. Recognition method of thermal infrared images of plant canopies based on the characteristic registration of heterogeneous images. Comput. Electron. Agric. 2020, 177, 105678. [CrossRef]

20. Maes, W.H.; Steppe, K. Estimating evapotranspiration and drought stress with ground-based thermal remote sensing in agriculture: A review. J. Exp. Bot. 2012, 63, 4671-4712. [CrossRef]

21. Poirier-Pocovi, M.; Bailey, B.N. Sensitivity analysis of four crop water stress indices to ambient environmental conditions and stomatal conductance. Sci. Hortic. 2020, 259, 108825. [CrossRef]

22. Allen, R.G.; Pereira, L.S.; Raes, D.; Smith, M. Others Crop Evapotranspiration-Guidelines for Computing Crop Water Requirements-FAO Irrigation and Drainage Paper 56; FAO: Rome, Italy, 1998; Volume 300, ISBN 92-5-104219-5. 
23. Rovira-Más, F.; Saiz-Rubio, V.; Cuenca-Cuenca, A. Augmented Perception for Agricultural Robots Navigation. IEEE Sens. J. 2020. [CrossRef]

24. Trout, T.J.; Johnson, L.F.; Gartung, J. Remote sensing of canopy cover in horticultural crops. HortScience 2008, 43, 333-337. [CrossRef]

25. Williams, L.E.; Ayars, J.E. Grapevine water use and the crop coefficient are linear functions of the shaded area measured beneath the canopy. Agric. For. Meteorol. 2005, 132, 201-211. [CrossRef]

26. Rouse, J.W.; Haas, R.H.; Schell, J.A.; Deering, D.W. Monitoring vegetation systems in the Great Plains with ERTS. NASA Spec. Publ. 1974, 351, 309.

27. Peñuelas, J.; Pinol, J.; Ogaya, R.; Filella, I. Estimation of plant water concentration by the reflectance water index WI (R900/R970). Int. J. Remote Sens. 1997, 18, 2869-2875. [CrossRef]

28. González-Fernández, A.B.; Rodríguez-Pérez, J.R.; Marabel, M.; Álvarez-Taboada, F. Spectroscopic estimation of leaf water content in commercial vineyards using continuum removal and partial least squares regression. Sci. Hortic. 2015, 188, 15-22. [CrossRef]

29. Bourgeon, M.A.; Gée, C.; Debuisson, S.; Villette, S.; Jones, G.; Paoli, J.N. «On-the-go» multispectral imaging system to characterize the development of vineyard foliage with quantitative and qualitative vegetation indices. Precis. Agric. 2016, 1-16. [CrossRef]

30. Ecarnot, M.; Compan, F.; Roumet, P. Assessing leaf nitrogen content and leaf mass per unit area of wheat in the field throughout plant cycle with a portable spectrometer. Field Crop. Res. 2013, 140, 44-50. [CrossRef]

31. Williams, L.E.; Araujo, F.J. Correlations among predawn leaf, midday leaf, and midday stem water potential and their correlations with other measures of soil and plant water status in Vitis vinifera. J. Am. Soc. Hortic. Sci. 2002, 127, 448-454. [CrossRef]

32. Girona, J.; Mata, M.; Del Campo, J.; Arbonés, A.; Bartra, E.; Marsal, J. The use of midday leaf water potential for scheduling deficit irrigation in vineyards. Irrig. Sci. 2006, 24, 115-127. [CrossRef]

33. Williams, L.E. Leaf water potentials of sunlit and/or shaded grapevine leaves are sensitive alternatives to stem water potential. J. Int. Sci. Vigne Vin 2012, 46, 207-219. [CrossRef]

34. Sebastian, B.; Baeza, P.; Santesteban, L.G.; de Miguel, P.S.; De La Fuente, M.; Lissarrague, J.R. Response of grapevine cv. Syrah to irrigation frequency and water distribution pattern in a clay soil. Agric. Water Manag. 2015, 148, 269-279. [CrossRef]

35. Dayer, S.; Herrera, J.C.; Dai, Z.; Burlett, R.; Lamarque, L.J.; Delzon, S.; Bortolami, G.; Cochard, H.; Gambetta, G.A. Nighttime transpiration represents a negligible part of water loss and does not increase the risk of water stress in grapevine. Plant. Cell Environ. 2021, 44, 387-398. [CrossRef]

36. Dayer, S.; Scharwies, J.D.; Ramesh, S.A.; Sullivan, W.; Doerflinger, F.C.; Pagay, V.; Tyerman, S.D. Comparing hydraulics between two grapevine cultivars reveals differences in stomatal regulation under water stress and exogenous ABA applications. Front. Plant Sci. 2020, 11, 705. [CrossRef]

37. Geladi, P.; Kowalski, B.R. Partial least-squares regression: A tutorial. Anal. Chim. Acta 1986, 185, 1-17. [CrossRef]

38. Di Rienzo, J.; Casanoves, F.; Balzarini, M.; Gonzalez, L.; Tablada, M.; Robledo, C. Infostat versión 2019; Centro de Transferencia InfoStat, FCA, Universidad Nacional de Córdoba: Córdoba, Argentina. Available online: http:/ /www.infostat.com.ar (accessed on 26 May 2021).

39. Earls, J.; Dixon, B. Spatial interpolation of rainfall data using ArcGIS: A comparative study. In Proceedings of the 27th Annual ESRI International User Conference, San Diego, CA, USA, 18-22 June 2007; Volume 31.

40. Leeuwen, C.V.; Tregoat, O.; Choné, X.; Bois, B.; Pernet, D.; Gaudillére, J.-P. Vine water status is a key factor in grape ripening and vintage quality for red bordeaux wine. How can it be assessed for vineyard management purposes? OENO One 2009, 43, 121-134. [CrossRef]

41. Sadler, E.J.; Evans, R.; Stone, K.C.; Camp, C.R. Opportunities for conservation with precision irrigation. J. Soil Water Conserv. 2005, $60,371-378$.

42. O'Shaughnessy, S.A.; Evett, S.R.; Colaizzi, P.D. Dynamic prescription maps for site-specific variable rate irrigation of cotton. Agric. Water Manag. 2015, 159, 123-138. [CrossRef]

43. Santos Valle, S.; Kienzle, S. Agriculture 4.0- Agricultural Robotics and Automated Equipment for Sustainable Crop Production; Integrated Crop Management; FAO: Rome, Italy, 2020; ISSN 1020-4555.

44. Boshoff, C.J. A Study of the Interaction between Grapevine Vigour and Water Status for Vitis Vinifera L. co Merlot Noir in Stellenbosch; University of Stellenbosch: Stellenbosch, South Africa, 2010.

45. García-Tejero, I.F.; Costa, J.M.; Egipto, R.; Durán-Zuazo, V.H.; Lima, R.S.N.; Lopes, C.M.; Chaves, M.M. Thermal data to monitor crop-water status in irrigated Mediterranean viticulture. Agric. Water Manag. 2016, 176, 80-90. [CrossRef]

46. Gonzalez-Dugo, V.; Zarco-Tejada, P.J.; Intrigliolo, D.S.; Ramírez-Cuesta, J.M. Normalization of the crop water stress index to assess the within-field spatial variability of water stress sensitivity. Precis. Agric. 2021, 22, 964-983. [CrossRef]

47. Sepúlveda-Reyes, D.; Ingram, B.; Bardeen, M.; Zúñiga, M.; Ortega-Farías, S.; Poblete-Echeverría, C. Selecting Canopy Zones and Thresholding Approaches to Assess Grapevine Water Status by Using Aerial and Ground-Based Thermal Imaging. Remote Sens. 2016, 8, 822. [CrossRef]

48. Sadler, E.J.; Camp, C.R.; Evans, D.E.; Millen, J.A. Corn canopy temperatures measured with a moving infrared thermometer array. Trans. ASAE 2002, 45, 581. [CrossRef]

49. Falkenberg, N.R.; Piccinni, G.; Cothren, J.T.; Leskovar, D.I.; Rush, C.M. Remote sensing of biotic and abiotic stress for irrigation management of cotton. Agric. Water Manag. 2007, 87, 23-31. [CrossRef] 
50. Peters, R.T.; Evett, S.R. Automation of a center pivot using the temperature-time-threshold method of irrigation scheduling. J. Irrig. Drain. Eng. 2008, 134, 286-291. [CrossRef]

51. O'Shaughnessy, S.A.; Evett, S.R. Canopy temperature based system effectively schedules and controls center pivot irrigation of cotton. Agric. Water Manag. 2010, 97, 1310-1316. [CrossRef]

52. García-Tejero, I.F.; Rubio, A.E.; Viñuela, I.; Hernández, A.; Gutiérrez-Gordillo, S.; Rodríguez-Pleguezuelo, C.R.; Durán-Zuazo, V.H. Thermal imaging at plant level to assess the crop-water status in almond trees (cv. Guara) under deficit irrigation strategies. Agric. Water Manag. 2018, 208, 176-186. [CrossRef]

53. Idso, S.B.; Jackson, R.D.; Pinter, P.J.; Reginato, R.J.; Hatfield, J.L. Normalizing the stress-degree-day parameter for environmental variability. Agric. Meteorol. 1981, 24, 45-55. [CrossRef]

54. Jones, H.G. Use of infrared thermometry for estimation of stomatal conductance as a possible aid to irrigation scheduling. Agric. For. Meteorol. 1999, 95, 139-149. [CrossRef]

55. Poirier-Pocovi, M.; Volder, A.; Bailey, B.N. Modeling of reference temperatures for calculating crop water stress indices from infrared thermography. Agric. Water Manag. 2020, 233, 106070. [CrossRef]

56. Bellvert, J.; Zarco-Tejada, P.J.; Marsal, J.; Girona, J.; González-Dugo, V.; Fereres, E. Vineyard irrigation scheduling based on airborne thermal imagery and water potential thresholds. Aust. J. Grape Wine Res. 2016, 22, 307-315. [CrossRef]

57. Costa, J.M.; Ortuño, M.F.; Lopes, C.M.; Chaves, M.M. Grapevine varieties exhibiting differences in stomatal response to water deficit. Funct. Plant Biol. 2012, 39, 179-189. [CrossRef]

58. Gonzalez-Dugo, V.; Zarco-Tejada, P.; Berni, J.A.J.; Suárez, L.; Goldhamer, D.; Fereres, E. Almond tree canopy temperature reveals intra-crown variability that is water stress-dependent. Agric. For. Meteorol. 2012, 154, 156-165. [CrossRef]

59. Martínez-Vilalta, J.; Poyatos, R.; Aguadé, D.; Retana, J.; Mencuccini, M. A new look at water transport regulation in plants. New Phytol. 2014, 204, 105-115. [CrossRef] [PubMed]

60. Grant, O.M.; Ochagavía, H.; Baluja, J.; Diago, M.P.; Tardáguila, J. Thermal imaging to detect spatial and temporal variation in the water status of grapevine (Vitis vinifera L.). J. Hortic. Sci. Biotechnol. 2016, 91, 43-54. [CrossRef]

61. Ben-Gal, A.; Agam, N.; Alchanatis, V.; Cohen, Y.; Yermiyahu, U.; Zipori, I.; Presnov, E.; Sprintsin, M.; Dag, A. Evaluating water stress in irrigated olives: Correlation of soil water status, tree water status, and thermal imagery. Irrig. Sci. 2009, 27, 367-376. [CrossRef]

62. Alchanatis, V.; Cohen, Y.; Cohen, S.; Moller, M.; Sprinstin, M.; Meron, M.; Tsipris, J.; Saranga, Y.; Sela, E. Evaluation of different approaches for estimating and mapping crop water status in cotton with thermal imaging. Precis. Agric. 2010, 11, $27-41$. [CrossRef] 